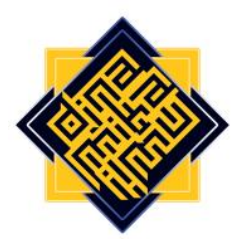

\title{
Exploring Saudi College Students' Attitudes toward Using English Dictionaries at Albaha University
}

\author{
Elsadig Mohamed Khalifa \\ Albaha University, Albaha, Saudi Arabia \\ e-mail:Sadig_99@yahoo.com
}

\section{Abstract}

The present paper addresses the attitudes of Saudi students toward using English dictionaries at Albaha University. A sample of 64 English majors in the College of Science and Arts in Almandaq took part in this study. A descriptive quantitative approach was implemented in this study. A 24-item questionnaire was applied in this study to collect the data. Data analysis was conducted using SPSS. Findings revealed that while most of the participants used bilingual dictionaries, few of them used monolingual dictionaries. Also, the findings showed that there was a lack of awareness among the students in using dictionary entries. Furthermore, a majority of students believe in the importance of using dictionaries for language learning. Integrating lexicography in the English course program is the main recommended implication to be taught. Teachers should implement activities related to dictionary skills in their English classes, such as using dictionary entries, including pronunciation, collocation, parts of speech, abbreviations, etc. Finally, students should be trained to use monolingual dictionaries in their language learning. These implications can be used to overcome the students' difficulties in using dictionaries.

Keywords: bilingual, dictionary, electronic, entries, monolingual

\section{A. Introduction}

Since the mid-2oth century, using English language dictionaries has been crucial for language learning and vocabulary building. Sue Atkins et al. (1987) was the first who ran a study aimed at revealing English as a foreign language (EFL) learners' use of bilingual and 


\section{Elsadig Mohamed Khalifa}

monolingual dictionaries. Besides, Hartmann, R. (1989) was the first scholar who wrote a research paper about dictionary users in which he presented a good summary in the state of arts concerning the use of dictionaries. He also puts forward a research hypothesis to enhance the research approaches.

A dictionary is a reference book that includes most of the words in a particular language, usually arranged alphabetically, including information about a word's form, pronunciation, function, meaning, etymology, spelling, and idiomatic uses (Ece Sarigul, 2016). The use of dictionaries is crucial in the learning/ teaching process because it is a very useful resource that helps learners to be independent of instructors. It can effectively provide valuable benefits to university students in in language learning (Al Sayed \& Siddiek, 2018). In addition, the dictionary contains words and their meanings, spellings, pronunciations, synonyms, antonyms, classes (parts of speech), collocations, etc. However, EFL students in the Faculty of Science and Arts, in Almandaq are unaware of the information contained in dictionaries when they use them. They only seek for the meanings of words.

One of the most important aims of students is to become independent, self-sufficient learners who can stay learning and developing their skills during their study. As a result, this study aims at helping students to learn independently by using some resources as a dictionary. So, a dictionary enhances a student to develop good learning habits for his career (Courtney, E. 2016). Recently, EFL lexicography has improved greatly and is now a prosperous field of EFL/SLA. It focused on the nature of the lexicon and vocabulary learning regularly related to dictionaries (e.g. Lewis, 1997; Nation, 2001; Schmitt, 2007). Also, the area has a relation to the study and analysis of corpus linguistics as well.

English lexicography is the process of writing, editing, and implementation of dictionaries in language learning (Nordquist, R. 2019). Most learners in the field of lexicography focus on the use of dictionary entries and other lexicography-related elements. However, using dictionaries will be incomplete without considering the users. This study investigates attitudes and beliefs about using dictionaries in the above-mentioned college

The current study tries to investigate the attitudes of Saudi EFL students toward using different types of dictionaries. It attempts to answer the following questions:

1. What type of dictionaries do students prefer?

2. Do students have an awareness of dictionary entries?

3. Do students encounter difficulties when they use dictionaries?

\section{B. Literature Review}

\section{Development of Research on a Dictionary Use}

Studies on research use cover four major areas: dictionaries typology, dictionary users, users' needs analysis, and users' skills analysis (Hartmann 1987: 154). In his study, Hartmann has focused on categorizing dictionaries, users, their needs, and skills. Research on the use of dictionaries has developed recently. It started in the 1960s, and in the 1990s, it became a separate area of study. All of these studies have focused on printed dictionaries. However, research on electronic dictionaries started at the beginning of the $21^{\text {st }}$ century. Electronic 
dictionaries differ from printed ones in the ways through which data can be stored and accessed (Topel A. (2014).

\section{Previous Studies}

This section will review previous literature related to the use of dictionaries to identify the impact of EFL dictionary use on the process of language learning and teaching. Ayoub, M. and lqbal, Z.(2020) investigated learners' attitudes and preferences over Siraiki dictionaries. The study employed a descriptive quantitative approach. Two hundred thirty students, including males and females, participated in this study. They filled out a questionnaire as the main tool of this study. Findings revealed that only 58 learners out of 230 have dictionaries. Most of the participants think that using a dictionary wastes time. All of them need training in using dictionaries.

Alhatmi, S. (2019) ran a study investigating dictionary use strategies to consult dictionaries for Saudi students. Subjects of the study were go students enrolled in English courses in the Department of European Languages in the Faculty of Arts at King Abdulaziz University in Jeddah, Saudi Arabia. The researcher ran a questionnaire for data collection. Findings revealed that the strategy of participants' preferences was greatly influenced by their likeness of features such as the easiness of search and use of electronic dictionaries, or their dislikes such as difficulties of search and use of paper dictionaries. Also, it was found that when students want to consult dictionaries, they search directly online or download an electronic dictionary on their mobile devices. The students used digital dictionaries more than paper dictionaries.

Ayoub et al. (2017) attempted to explore the difficulties of using dictionaries and dictionary using habits among secondary school Urdu students in Pakistan. The research was descriptive and qualitative. They presented a questionnaire and an interview for both learners and instructors, respectively. The results showed that subjects of this study use dictionaries only for finding word meanings. They did are not aware of other dictionary users. They also concluded that dictionaries are important for language learning and for learning English literature.

Sarigul, E. (2016) studied the importance of using dictionaries in language learning and teaching for Turkish university students. The study found out that in most classrooms, little time is given to using dictionaries. Also, it showed that while most of the students used bilingual dictionaries, the instructors preferred to use monolingual ones. It is recommended that dictionary training should be an important part of the language syllabus.

Nesi, H. and Haill, R.(2015) studied the use of dictionary habits among international students using English as the study medium in a British University. They also investigated the ways the participants consulted dictionaries to check unknown word meanings. The study findings showed that more than $50 \%$ of the participants failed in the dictionary consultations. They found some difficulties in understanding dictionary entries and subentries.

Al Sayed \& Siddiek (2018) explored Sudanese students' attitudes toward pedagogical dictionaries. The respondents of the study were 160 Sudanese university students enrolled 


\section{Elsadig Mohamed Khalifa}

in English courses in three Sudanese universities. They ran a questionnaire as the main tool for this study. Findings of the study revealed that the respondents have tremendous awareness of the significance of a dictionary for learning languages. It was also found that most of the students preferred to use Bilingual and electronic dictionaries more than monolingual dictionaries. Besides, they lacked knowledge of using some dictionary entries such as abbreviations and organization of definitions.

The study by Chen, Y. (2010) compared the usage of an electronic pocket dictionary and a paper dictionary among Chinese university students. Also, it investigated the impact of using dictionaries on learning vocabulary. The study results explored some variances between the use of electronic and paper dictionaries. The usage of the former is significantly faster than the latter one. However, no significant differences exist between them in learning vocabulary and comprehension

Mansoor, H., and Ahmed, A. (2010) explored dictionary using habits among 100 medical students from Lahore. The study is quantitative. They administered a questionnaire to the study sample. Results showed that medical students use dictionaries only for language needs. They were not aware of using dictionary entries such as pronunciations, paraphrasing, or parts of speech. They only used dictionaries for language information or word meanings.

\section{Research Methodology}

\section{Population and Sample}

Samples of this study were chosen from students who major in the English language in the College of Science and Arts at Albaha University in the first term of (2020). The number of students in the English Department is a bit small. So, 64 participants out of 91 students responded to the electronic questionnaire and were considered as the study subjects.

\section{Procedures}

A pilot study was applied to five students who enrolled in applied linguistics courses in the English Department, Faculty of Science and Arts, Almandaq, Albaha University. It results in some modifications concerning some statements included in the tool of the study. As a result, the tool was prepared in its final version. Then, the researcher prepared an electronic Google form version and sent it to the subjects in the first term of 2020/2021. Only 64 out of 91 students responded to the questionnaire and sent their feedback which is considered as the main sample for this research. The researcher acted as the main examiner, received subjects' answers, and use them to prepare the data for analysis.

\section{Instrument}

To achieve the aims, a questionnaire that focuses on the importance of using dictionaries, their types (monolingual and bilingual dictionaries, and difficulties encountered by students when they use them. To answer the study questions, a quantitative method was used. A 24-item questionnaire adapted from the classic study by Bejoint (1981), 
and modified by Hartmann (2005) is presented to junior college students English majors in the College of Science and Arts in Almandaq in the first term of (2020). The instrument was designed, in such a way, to extract students' views about the use of dictionaries in language learning in general, and assessing students' use of dictionary entries, and rating them in particular.

A questionnaire containing four parts is considered as the main instrument for this study. It addresses students' beliefs, evaluations, habits, and how they rate dictionaries. It includes 24 items adapted from Benjoints' (1981) classic study. The instrument is divided into four parts: part (1) contains seven statements addressing learners' beliefs about the use of dictionaries. Part (2) consists of eight statements evaluating students' use of dictionary types. Part (3) includes four statements relating to students' rating of dictionaries. Part (4) comprises five statements concerning students' habits of buying different types of dictionaries.

\section{Validity of the Questionnaire:}

\begin{tabular}{|c|c|c|c|}
\hline & & $\mathrm{N}$ & $\%$ \\
\hline \multirow[t]{3}{*}{ Cases } & Valid & 27 & 84.4 \\
\hline & Excluded & 5 & 15.6 \\
\hline & Total & 32 & 100.0 \\
\hline
\end{tabular}

a. List-wise deletion based on all variables in the procedure.

The instrument validity is measured using the case processing summary based on all variables in the procedures. Table (1) above shows that the validity of the questionnaire is 84.4 , which is very high.

\section{Reliability:}

Table (2): Reliability Statistics

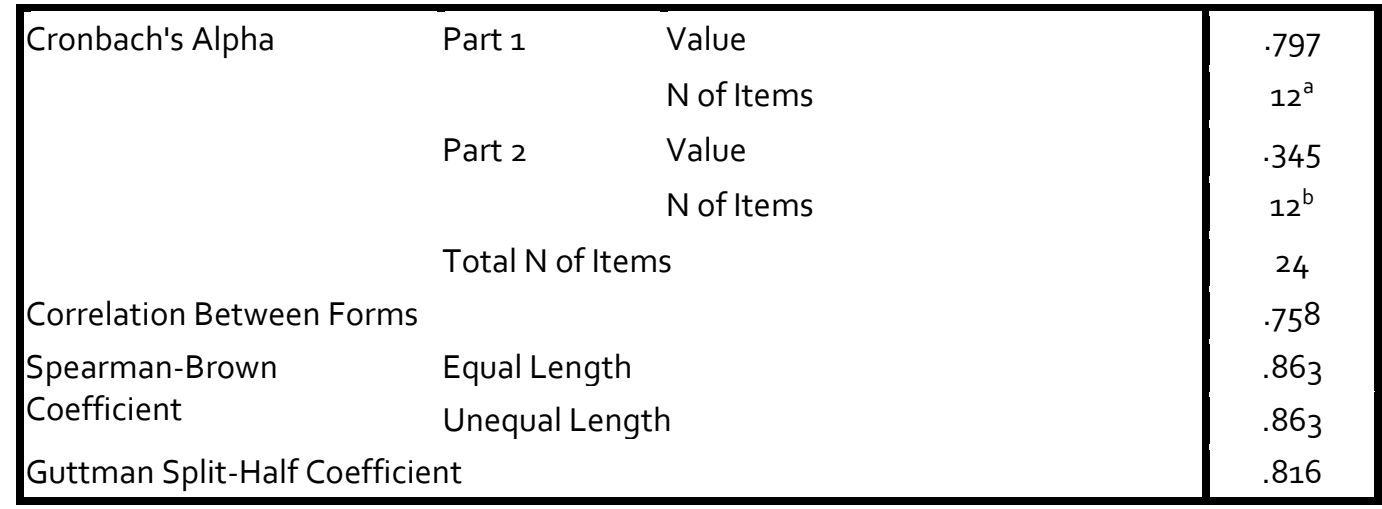

a. The items are: var1, var2, var3, var4, var5, var6, var7, var8, var9, var10, var11, var12.

b. The items are: var13, var14, var15, var16, var17, var18, var19, var20, var21, var22, v23, v24. 


\section{Elsadig Mohamed Khalifa}

By using SPSS, Table (2) above shows that Cronbach's Alpha is (.797), and the correlation between forms is (.758). Also, Spearman-Brown Coefficient is (.863), and Guttman Split-half Coefficient is (.816). These results reveal that the instrument of the study is highly reliable.

\section{Findings}

The purpose of the study instrument is to evaluate the students' attitudes and their responses to the various parts of using dictionaries. Its four parts represent the variables that are going to be dealt with. This section contains data analysis, results, and discussion as follows:

\section{Results of the First Part of the Questionnaire}

Table (3): Underlying beliefs about dictionaries

\begin{tabular}{|c|c|c|c|c|c|c|c|c|}
\hline Options & 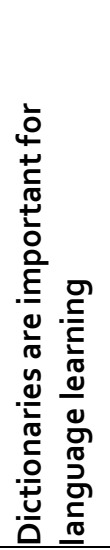 & 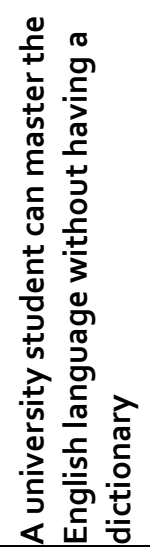 & 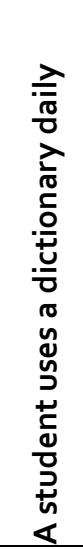 & 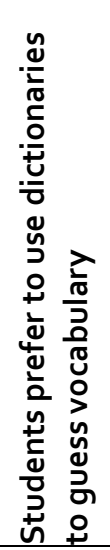 & 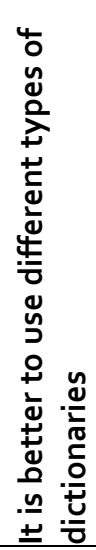 & 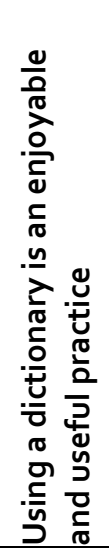 & 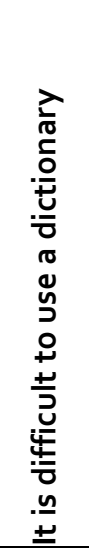 & 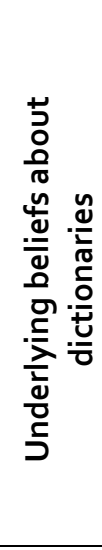 \\
\hline $\begin{array}{l}\text { Strongly } \\
\text { disagree }\end{array}$ & 9.4 & 25 & 9.4 & 6.2 & 18.8 & 3.1 & 25 & 13.84 \\
\hline Disagree & 0 & 28.1 & 3.1 & 6.2 & 15.6 & 6.2 & 40.6 & 14.26 \\
\hline Neutral & 6.2 & 28.1 & 40.6 & 25 & 15.6 & 21.9 & 18.8 & 22.31 \\
\hline Agree & 46.9 & 18.8 & 28.1 & 43.8 & 31.2 & 28.1 & 3.1 & 28.57 \\
\hline $\begin{array}{l}\text { Strongly } \\
\text { Agree }\end{array}$ & 37.5 & 0 & 18.8 & 18.8 & 18.8 & 40.6 & 12.5 & 21.00 \\
\hline Total & 100 & 100 & 100 & 100 & 100 & 100 & 100 & 100.00 \\
\hline
\end{tabular}

The first statement concerns the importance of dictionaries for language learning. The respondents' responses are of great value because (84.4\%) strongly agree and agree with that statement which leaves no doubt about the necessity of using dictionaries in language learning. These findings indicate that students use dictionaries in learning English and in their study in general. Enthusiastically, this result answers the first question that dictionaries are significant for the process of language learning. 
The second statement is about mastering EFL without using dictionaries. However, (\%56.2) disagree with this statement which means they cannot master the English language without using a dictionary. This result means that dictionaries are important elements for mastering foreign languages. Furthermore, statement (3) concerns the daily use of dictionaries. About $47 \%$ of the participants use a dictionary every day for their learning purposes. Also, results show that more than $50 \%$ of the study sample lack the awareness of implementing dictionaries for their daily use of the English language.

As specified in the statement (4), about $62.6 \%$ of the study sample prefers to use a dictionary to guess vocabulary meanings. However, only $12.4 \%$ of students do not prefer to use the dictionary to guess the meanings of vocabulary words. These results support the argument of (Scholfield, 2002) that learners can use a dictionary as the main source of language acquisition. This is a piece of strong evidence that most of the students use guessing as a technique for acquiring vocabulary and for comprehension purposes.

Results of the statement (5) show that $50 \%$ of the participants use different types of dictionaries, mainly bilingual and monolingual ones. These findings do not show any statistical significance because $50 \%$ of the study sample use one type of dictionary only. Regarding the use and enjoyment of dictionaries (statement 6 ), $68.7 \%$ of students give positive responses. They revealed that they prefer using a dictionary rather than enjoying it after they were questioned by the study designer. These responses mean dictionaries are useful language tools that help in language learning. On the other hand, statement (7) is about the difficulties of using a dictionary. Findings reveal that only $15.6 \%$ of students face some difficulties in using dictionaries. Surprisingly, these results indicate that the study samples are highly aware of using dictionaries without any problems.

The overall results of the students' beliefs about using dictionaries (graph, 1) above show that $50 \%$ of the study participants believe that using dictionaries can improve their reading comprehension and expand their vocabulary learning. However, about $28 \%$ of them did not believe in the importance of dictionaries in enhancing language learning, and 22\% were not sure about the significance of using dictionaries. Giving answers to the first questions, these results of part one's statements have confirmed the students' positive beliefs about using dictionaries. These findings go in line with Al Sayed \& Siddiek's (2018) study findings which showed positive attitudes of Sudanese university students' beliefs towards using a dictionary. Also, it is similar to the study's results of Nesi, $\mathrm{H}$. and Haill, R. (2002), who investigated dictionary usage by international learners at a British University. 


\section{Elsadig Mohamed Khalifa}

\section{Results of the Instrument's Second Part}

Table (4): Assessment of dictionary's types

\begin{tabular}{|c|c|c|c|c|c|c|c|c|c|}
\hline Options & 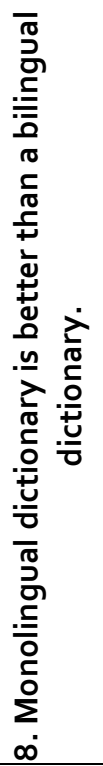 & 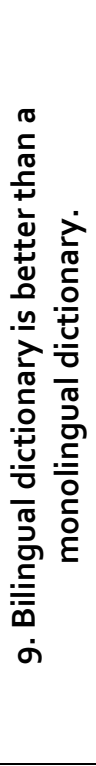 & 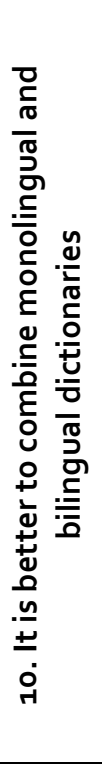 & 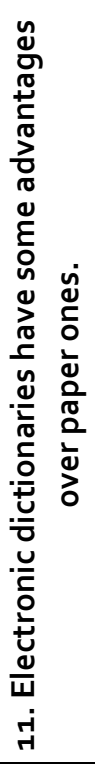 & 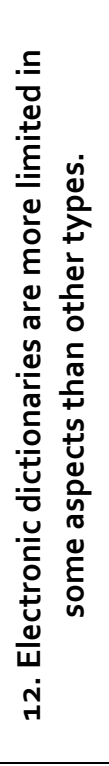 & 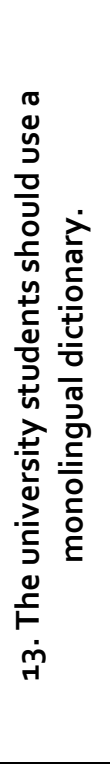 & 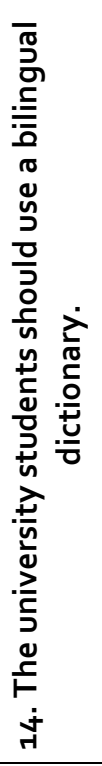 & 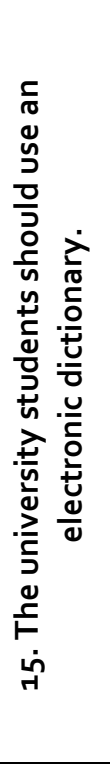 & 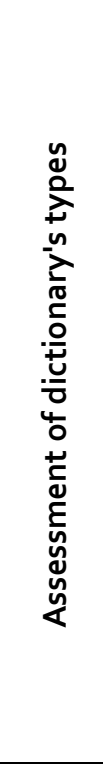 \\
\hline $\begin{array}{l}\text { Strongly } \\
\text { disagree }\end{array}$ & 15.6 & 3.1 & $9 \cdot 4$ & 3.1 & 6.2 & 6.2 & 18.8 & 12.5 & 9.36 \\
\hline Disagree & 21.9 & 18.8 & 9.4 & 12.5 & 18.8 & 12.5 & 9.4 & 12.5 & 14.48 \\
\hline Neutral & 43.8 & 12.5 & 31.2 & 28.1 & 31.2 & 50 & 15.6 & 21.9 & 29.29 \\
\hline Agree & 12.5 & 43.8 & 37.5 & 34.4 & 21.9 & 25 & 21.9 & 31.2 & 28.53 \\
\hline $\begin{array}{l}\text { Strongly } \\
\text { Agree }\end{array}$ & 6.2 & 21.9 & 9.4 & 21.9 & 21.9 & 6.2 & 34.4 & 21.9 & 17.98 \\
\hline Total & 100 & 100 & 100 & 100 & 100 & 100 & 100 & 100 & 100.00 \\
\hline
\end{tabular}

To answer the second study question, the second part of the questionnaire has focused on the students' views about the different types of dictionaries. The main focus is on the differences between monolingual and bilingual dictionaries. Table (4) above reveals the results of eight statements which are included in the second part of the instrument. Results of the statement (8) show that only $18.7 \%$ of the participants think that a monolingual dictionary is better than a bilingual dictionary. Whereas $65.7 \%$ of them prefer to use a bilingual dictionary as the best type as they respond to statement (9). This is reflected in statement (14) responses which shows that $56.3 \%$ of students view that university students should use a bilingual dictionary as a learning instrument. These findings mean that subjects of the study prefer to use the English-Arabic dictionary more than using the English-English dictionary. These results have some contradictions with the study's results of Al Sayed \& Siddiek's (2018), who have found out that students prefer to use monolingual dictionaries more. Also, findings of statement (13) analysis show that $31.2 \%$ 
choose to use monolingual dictionaries. Statement (10) findings show that $46.9 \%$ of the students use both monolingual and bilingual dictionaries.

On the other hand, to answer question three, statement (11) contrasts between electronic and paper dictionaries. Statistics reveal that $56.3 \%$ of the respondents' responses indicate that an electronic dictionary has more advantages than a paper dictionary. They think that the former saves time while the latter wastes time. These findings have aligned with the study of Alhatmi, S. (2019) in which samples have confirmed the easiness of search on electronic dictionaries and faced some difficulties in using a paper dictionary. Concerning the limitation of dictionaries, as stated in (12), results show that $46.8 \%$ of the students argue that an electronic dictionary is more limited in some features than a paper dictionary. In the latter, a learner can find more word entries than the former one. These findings can also be supported by the responses of the study samples for statement (15) in which a slight majority of participants (53.1\%) think that an electronic dictionary should be used by university students.

\section{Results of Part Three}

Table (5): Buying dictionaries

\begin{tabular}{|c|c|c|c|c|c|c|}
\hline Options & 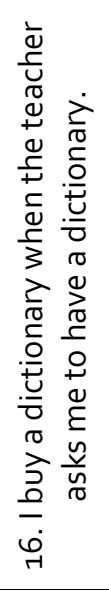 & 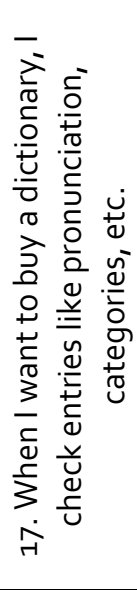 & 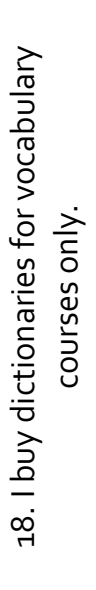 & 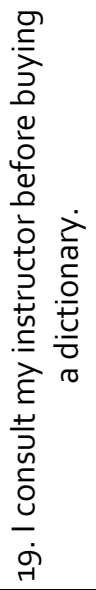 & 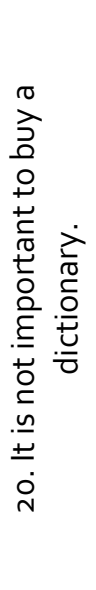 & 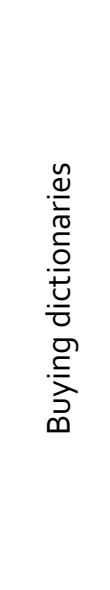 \\
\hline Strongly disagree & 17.24 & 6.7 & 16.7 & 17.2 & $33 \cdot 3$ & 18.23 \\
\hline Disagree & 24.14 & 6.7 & 33.3 & 17.2 & 26.7 & 21.61 \\
\hline Neutral & 27.59 & 33.3 & 20 & 20.7 & 16.7 & 23.66 \\
\hline Agree & 20.69 & 30 & 13.3 & 20.7 & 20 & 20.94 \\
\hline Strongly Agree & 10.34 & 23.3 & 16.7 & 24.1 & $3 \cdot 3$ & 15.55 \\
\hline Total & 100 & 100 & 100 & 100 & 100 & 100.00 \\
\hline
\end{tabular}

Table (5) above concerns the analysis of students' habits of buying certain dictionaries rather than others. Findings of the statement (16) reflect that $31 \%$ of the study sample strongly agree and agree to buy dictionaries occasionally in case the instructor asks them to have a dictionary, whereas $41.38 \%$ have already purchased dictionaries without any order 


\section{Elsadig Mohamed Khalifa}

from their language teachers. These findings strongly support the importance of using a dictionary, as stated in statements (8 and 9).

Concerning knowledge about dictionary entries such as pronunciations, parts of speech, etc., results of the statement (17) show that about $53 \%$ of the participants know of dictionary entries, but only $\mathbf{1 3 . 4 \%}$ are not aware of them. They only check dictionaries for word meanings without considering pronunciations nor other categories. Besides, statement (18) regards the purpose behind buying a dictionary. While $30 \%$ buy dictionaries for vocabulary learning only, $48 \%$ aims at buying dictionary for word meanings, pronunciations, parts of speech, and other contextual usages. This means that a majority of students are aware of usages and knowledge about dictionaries.

Findings of the statement (19) reveal that $44.8 \%$ consult their instructors before buying a dictionary, 20.7 are not sure, and 34.4\% think that there is no need for consulting teachers before purchasing dictionaries. This indicates that the majority of the students are aware of the teachers' roles before buying dictionaries. Involving teachers in this process can help in purchasing useful dictionaries. On the other hand, statistics of the statement (20) illustrate that $60 \%$ of the sample strongly agree and agree with the importance of buying dictionaries, $20 \%$ are unsure, and $23.3 \%$ disagree because they are unaware of the importance of them.

\section{Results of the Fourth Variable}

Table (6): Rating dictionaries

\begin{tabular}{|c|c|c|c|c|c|}
\hline Options & $\begin{array}{l}\text { 21. How do } \\
\text { you rate the } \\
\text { monolingual } \\
\text { dictionaries }\end{array}$ & $\begin{array}{l}\text { 22. How do you } \\
\text { rate the bilingual } \\
\text { dictionaries }\end{array}$ & $\begin{array}{l}\text { 23. How do you } \\
\text { rate the } \\
\text { electronic } \\
\text { dictionaries }\end{array}$ & $\begin{array}{l}24 . \text { How do you } \\
\text { rate a paper } \\
\text { dictionary }\end{array}$ & $\begin{array}{c}\text { Rating } \\
\text { dictionaries }\end{array}$ \\
\hline Poor & 3.1 & 0 & 0 & 9.4 & 3.14 \\
\hline Not sure & 0 & 6.2 & 3.1 & 6.2 & 3.88 \\
\hline Good & 46.9 & 28.1 & 25 & 12.5 & 28.13 \\
\hline Very good & $37 \cdot 5$ & 21.9 & 31.2 & $37 \cdot 5$ & 32.04 \\
\hline Excellent & 12.5 & 43.8 & 40.6 & 34.4 & 32.83 \\
\hline Total & 100 & 100 & 100 & 100 & 100.00 \\
\hline
\end{tabular}

Table (6) above concerns rating dictionaries. These four questions ask about the ranking of dictionaries. The findings show that only $12.5 \%$ think that a monolingual dictionary is excellent, $37.5 \%$ view that it is very good, and $3.1 \%$ argue that it is poor. In contrast, $43.8 \%$ believe that a bilingual dictionary is excellent, $21.9 \%$ think that it is a very good instrument, and no student believes that as poor. These findings confirmed that most of the students prefer to use a bilingual dictionary more than a monolingual dictionary. This result may explain many students' weaknesses in language performance.

To compare between electronic and paper dictionaries, 40.6\% hold electronic dictionaries to be excellent, $31.2 \%$ as very good, and no participant think of them as poor. 
However, $34.4 \%$ view that a paper dictionary is excellent, $37.5 \%$ rating them as very good instruments, and $9.4 \%$ think of them as poor tools for learning a language. These findings confirmed the superiority of electronic dictionaries over paper ones.

\section{E. Discussion}

In contrast, it is observable that some similarities and differences can be found between the findings of this study and other ones. It is similar to the study of Nesi, $\mathrm{H}$. and Haill, R. (2015) in which students found difficulties in understanding dictionary entries and subentries., and Mansoor, H., and Ahmed, A. (2010) who found that students lack awareness of using dictionary entries. Also, it is aligned with Al Sayed \& Siddiek (2018) who concluded that students lack dictionary skills. But, it differs in some of their findings concerning types and preference of dictionaries. Most of their participants prefer using a monolingual dictionary, whereas our study sample prefers to use bilingual dictionaries. They also lack knowledge of using some dictionary entries

Concerning the use of electronic dictionaries, these findings are similar to the study results of Alhatimi, S. (2019) who finds out that Saudi university students' prefer to use an electronic dictionary because of its easiness of search, or their dislike such as difficulties of searching and using of paper dictionaries. Concerning difficulties, the study findings are relevant to Ayoub and Iqbal's (2017) who discover that few students are aware of using dictionaries because they think that using a dictionary wastes time. They are also similar to the study findings of Sarigule (2016) which show that while most of the Turkish participants use bilingual dictionaries, instructors prefer to apply monolingual ones. Furthermore, these findings can support Chen, Y. (2010) results that the students prefer to use an electronic dictionary more than a paper one.

In sum, these results show that an obvious majority of the participants believe that bilingual English dictionaries are the best choice for them to learn English. Furthermore, a majority of students believe in the importance of using dictionaries for language learning. However, most of the study sample were unaware of using dictionary entries such as pronunciations, parts of speech, collocations, abbreviations, etc. They check dictionaries for word meanings only. It means that they lack dictionary knowledge. On the other hand, findings reveal most of the students prefer electronic dictionaries more than paper ones. They encounter some difficulties when they look up paper dictionaries, such as wasting time on vocabulary searching. They think that an electronic dictionary has quick search, so it saves their time.

\section{E. Conclusion}

The purpose of this paper is to investigate college students' attitudes toward using dictionaries by a representative sample of college junior students' English majors. To achieve this aim, the researcher ran a questionnaire. To answer questions one about types of dictionaries, the study results show that an obvious majority of the participants believe that bilingual English dictionaries are the best choice for them to learn English. Furthermore, a majority of students believe in the importance of using dictionaries for language learning. 


\section{Elsadig Mohamed Khalifa}

Concerning question two about dictionary's entries, most of the study sample were unaware of using dictionaries entries such as pronunciation, part of speech, collocation, abbreviations, etc. They check dictionaries for meaning only. This means that they lack dictionaries knowledge. On the other hand, findings reveal most of the students prefer electronic dictionaries more than paper ones. Finally, to answer question three, most of the students encounter some difficulties when they look up paper dictionaries, such as wasting time on vocabulary searching. They think that an electronic dictionary has quick search, so it saves their time. In light of the study findings, pedagogical implications are made. Firstly, it is recommended that lexicography should be integrated into the English courses program to be taught consciously as the main course in English Department. Secondly, teachers should integrate dictionary skills and related activities in their English classes, such as using dictionary entries including pronunciation, collocation, part of speech, abbreviations, etc. Finally, the students should be aware of using monolingual dictionaries rather than bilingual ones. These implications will be applicable and can help the students, teachers, and syllabus designers, and decisions makers to encounter difficulties faced by students when they use dictionaries to ultimately enhance their language learning.

\section{BIBLIOGRAPHY}

Alhatmi, S. (2019). A Survey Study of the Dictionary Use Sub-strategies of English Majors in Saudi Arabia: Dictionary Related Aspects. English Language Teaching, 12(3), 2019

Al Sayed, N. A. \& Siddiek, A.G. (2018). Investigating Students' Attitudes towards

Pedagogical Dictionaries: A Study of Sudanese English Majors. International Journal of Language and Linguistics. 5(3), 2018

Ayoub M. \& Iqbal Z. (2020). Attitudes and Preferences of Advanced Learners towards Siraiki

Dictionaries. International Journal of English Linguistics, 10(1), 2020

Bejoint, H. (1981). The foreign students' use of monolingual English dictionaries: A Study of language needs and reference skills, Applied Linguistics, 3: 207- 222.

Chen, Y. (2010). Dictionary Use and EFL Learning. A contrastive study of Pocket Electronic

Dictionaries and Paper Dictionaries, International Journal of Lexicography, 23 (3), doi:10.1093/ijl/ecq013.

Courtney, E. (2016). Advantages of using a dictionary. Langports Pty Ltd.

Hartmann, R. R. K. (1989). Sociology of the Dictionary User: Hypotheses and Empirical

Studies. In F. J. Hausmann, o. Reichmann, H. E. Wieg and, \& L. Zgusta (Eds.), International Dictionaries Handbook Lexicography (Vol. 1, pp. 102-111). de Gruyter

Hartmann, R.R.K. (1991). What is the Use of Learners' Dictionaries? Institute of Language in Education Journal, 8, p.73-83

Hartmann, R.R.K. (2005). Dictionaries and their Users. University of Exeter.

Lewis. M. (1997). Implementing the Lexical Approach. Language Teaching Publications. 
Mansoor, H. \& Ahmed, A. (2010). Purpose of dictionary use in professional education: A study of dictionary using habits in medical students. Procedia Social and Behavioral Sciences 2 (3988-3993). Elsevier.

Nation, I. (2001). Learning vocabulary in another language. Cambridge University Press.

Nesi, H. \& Haill, R. (2015). A study of dictionary use by international students at a British University. International Journal of Lexicography, 15(4): 277-305. http://dx.doi.org/10.1093/ij/15.4.277

Nordquist, R. (2019). Definitions and examples of lexicography. Retrieved from: https://www.thoughtco.com/what-is-lexicography-1691229

Sarigul, E. (2016). The Importance of Using Dictionary in Language Learning and Teaching. Selçuk University Journal of Faculty of Letters, SSRN 1300-4921, Selcuk University

Schmitt, N. (2007). Vocabulary in Language Teaching. Cambridge University Press.

Scholfield, P. (2002). Why Shouldn't Monolingual Dictionaries be as Easy to Use as Bilingual Ones? [Retrieved April 23, 2014, from http://www .Longman dictionaries/teacher/articles/.

Tono, Y. (2012). Research on Dictionary Use in the Context of Foreign Language Learning. De Gruyter Publishing

Topel, A. (2014). Review of research into the use of electronic dictionaries. Müller-Spitzer: Carolin (ed.): Using online dictionaries. Berlin: de Gruyter, 2014. (Lexicographical series major; 145), pp. 13-54. 